\title{
Austrian Cycle Theory and the Prospect of a Coordinationist Macroeconomics ${ }^{1}$
}

\author{
Richard E. Wagner
}

George Mason University

Someone who surveyed the literature on business cycles in the early 1930s, and who then jumped ahead just 20 years to survey the literature in the early 1950s, would surely be astonished by the stark contrast in the treatment accorded to Austrian formulations. In the 1930s, Austrian cycle theory held a prominent position in the efforts of economists to understand and explain business cycles. This can be seen readily by perusing such treatises as Alec Macfie (1934) and Gottfried Haberler (1937). Twenty years later, the standing of Austrian cycle theory had collapsed dramatically. Robert Gordon (1952), for instance, gave only a couple of pages of dismissive references to Austrian cycle theory in a treatise of some 700 pages. The bulk of the contemporary textbook literature does not mention Austrian contributions at all. Most of those texts portray a menu of options for macro theory that includes classical, Keynesian, monetarist, new classical, and new Keynesian, but which mention an Austrian contribution hardly at all.

There are a number of possible explanations that might be advanced for the evanescence of interest in Austrian cycle theory. One possibility is that Austrian cycle theory was not as readily assimilable to the growing demand for mathematical and econometric modeling that was entering economics around the same time. Another is that Austrian cycle theory clashed with the increasingly collectivist temper of the times that emerged in the 1930s and started to recede only in the 1960s. With a present recession attributed to a past inflation, an Austrian remedy of market-based liquidation had no chance against any remedy that called for yet more state-sponsored inflation. Yet a third possibility, one that I think can be dismissed readily, is that Austrian cycle theory fared quite poorly compared with other options, when those various theories were 
assessed against the world of experience.

Whatever the explanation, Austrian cycle theory did disappear from the analytical radar screen of the economics profession within a short period of time, and has yet to make any significant reappearance. At the same time, however, there has been a growing interest in a coordinationist approach to macroeconomics, an approach that differs severely from the single or representative agent approaches that have been so dominant in recent times. Austrian cycle theory is also a form of coordinationist macroeconomics, and it is plausible that a program of coordinationist macroeconomics could be advanced by some insights from a suitably renovated Austrian cycle theory.

This paper starts by presenting a stylized portrait of Austrian cycle theory at its apogee in the 1930s. The remainder of the paper explores some of the contours of a coordinationist macroeconomics, and notes some of the ways that considerations from Austrian cycle theory might advance a program of coordinationist macroeconomics. The central theme of the paper is that the central ideas of Austrian cycle theory still have merit, but only within the framework of a coordinationist approach to macroeconomics. At the same time, however, a coordinationist macroeconomics involves much more than restatements of Austrian cycle theory circa 1935.

\section{Austrian Cycle Theory: A Quick Review}

When people refer to Austrian cycle theory, they are referring primarily to an analytical framework initially articulated by Ludwig von Mises (1912) and refined by Friedrich Hayek (1935). This Mises-Hayek theory of the business cycle was in turn erected principally upon foundations laid by Eugon von Böhm-Bawerk (1884-89) and Knut Wicksell (1898). Central to Austrian cycle theory is a particular, capital-theoretic formulation of the capitalist production process, where the relationship between production processes that require different amounts of time is governed by the rate of interest. 
Most economists characterize production as taking place instantaneously, as illustrated by a production function that describes current production as a function of the amount of inputs currently applied. This common formulation yields the conventional circular flow of income that appears in nearly all the texts these days. In sharp contrast, Böhm-Bawerk described production as possessing a time structure. Inputs that were applied today would contribute to output only sometime in the future. When in the future this might occur would depend on where in the structure of production those inputs were applied. For instance, someone who constructed a plant to freeze-dry vegetables would contribute to an increased consumption of food more quickly than would someone who constructed a laboratory to do research on plant genetics, although the laboratory might eventually contribute more to food consumption than the freeze-drying plant.

An economy would be described as a river, where the volume of consumer goods that flow through the terminus depends on the amounts of water that enter from the various tributaries, and where those inflows do not reach the terminus without some passing of time. The rate of interest connects and renders consistent the prices of all goods within the structure of production. Böhm-Bawerk recognized that the rate of interest governed the structure of production within a society. If the rate of interest is, say, five percent, the structure of production will include some relative investment in plants to freeze-dry vegetables and laboratories to pursue research on plant genetics. Should that rate of interest be, say, eight percent instead, the structure of production will entail entail less capital invested in laboratories and more in freezers.

Wicksell subsequently distinguished two kinds of interest rate, a real rate and a loan rate. The real rate was a theoretical construct. It was the rate of interest that was consistent with equilibrium in the structure of production, as illustrated above. The loan rate was the rate of interest that was available on the market. If the loan rate diverged from the natural rate, a process of adjustment would be set in motion. This adjustment would continue until equality was restored between the two rates. For instance, suppose 
the loan rate were lower than the real rate. In the presence of this divergence, people would bid up the prices of capital goods and associated inputs. These increased demands would generate increases in money incomes, which in turn would lead to increased demands for consumer goods. The economic structure of production in the society would change, by becoming more roundabout in Böhm-Bawerk's unnecessary terminology. ${ }^{2}$

It is but a short distance from the formulations of Böhm-Bawerk and Wicksell to the Austrian theory of the cycle articulated by Mises and Hayek. In its inception, Austrian cycle theory looks like a standard monetarist explanation of expansion or contraction. In both cases, a monetary expansion quickens the pace of economic activity, while a monetary contraction slows it. What gives a different character to Austrian cycle theory is that the monetary disturbance affects the entire structure of production. For instance, an expansion of bank credit that drives the loan rate of interest below the real rate will upset the entire structure of price relationships within the economy. This change in the structure of price relationships will affect calculations of anticipated profitability throughout the economy, with relatively more roundabout projects becoming relatively more profitable. Both a plant to freeze-dry vegetables and a laboratory for research on plant genetics may appear more profitable after the loan rate falls below the natural rate, but the increase in profitability will be relatively stronger for the laboratory.

The initial impact of an expansion in bank credit, in the canonical Austrian formulations of the 1930s, is to lengthen the structure of production. This lengthening results because the decline in the loan rate of interest affects the entire structure of price relationships within the economy, by increasing relatively more strongly the anticipated profitability of projects whose eventual contribution to consumption are further removed in time. What happens next depends on the source of the expansion in bank credit. One possible source of credit expansion is a genuine reduction in time preferences among a significant set of people within the society. This increased desire to save would 
enable banks to expand their offerings of credit. The structure of production within the economy would lengthen as the economy moved to a more capital-intensive structure of production, and this new structure of production could be maintained so long as there were no further changes in time preference.

The alternative source of credit expansion is one that does not stem from an increase in saving. Even if there is no change in time preferences and desires to save, a central bank may pursue a program of credit expansion. The initial effect of this credit expansion is identical to the expansion that results from an increase in desires to save: the structure of production lengthens due to the increased relative profitability of more roundabout projects. This increased profitability, however, is not genuine but is only temporary. Time preferences are unchanged, so there has been no decreased desire for consumer goods. The lengthening in the structure of production reduces the relative supply of consumer goods. Without a decreased demand for consumer goods that would have accompanied a fall in time preferences, the prices of consumer goods will rise. This leads to revisions in entrepreneurial calculations of profitability, as the production of consumer goods now appears more attractive than it would have appeared had time preferences truly fallen. The structure of production thus shortens. If the original lengthening in the structure of production corresponds to the expansion phase in a business cycle, the subsequent shortening corresponds to the contraction phase. Both the initial expansion and the subsequent contraction are set in motion by the initial monetary expansion.

\section{Austrian Cycle Theory: Continuing Verities and Particularistic Obsolescence}

Austrian cycle theory pretty much reached canonical status in the mid-1930s, and subsequent expositions have been largely restatements. ${ }^{3}$ While Austrian cycle theory occupied a place of prominence in the 1930s, it had pretty much disappeared from economics by the 1950s. While there has been some resurgence of interest in Austrian 
economics over the past 20 years or so, that resurgence does not seem to have extended to Austrian cycle theory. ${ }^{4}$ While there are a number of explanations that might be advanced for the evanescence of Austrian cycle theory, I have no desire to pursue any effort at historical explanation here. My interest is rather to make some effort to distinguish between those aspects of Austrian cycle theory that are still valuable for macroeconomics today and those that are not.

Perhaps the two places where obsolescence most strongly dates the canonical formulations of Austrian cycle theory are the treatment of expectations and the process through which credit expansion generates economic expansion. As for expectations, even Wicksell wondered about the impact of expectations on the cumulative process. In these days of continual, large-scale financial observation and reporting, expectations must be incorporated into any theoretical enterprise. If the fate of an entrepreneurial undertaking were to depend on making an accurate distinction between credit creation by a central bank and an increase in saving, it is surely unreasonable to use a theoretical construction that ignores that distinction. If one element of rationality in expectation involves an effort to distinguish between the two different processes of credit expansion, people would treat the lower interest rate due to credit expansion as transitory, and would treat as permanent only the lower interest rate due to increased saving.

Austrian cycle theory must incorporate some requirement of rationality in expectation, in conjunction with a recognition that aggregate data are widely and readily reported. For a profession whose members almost universally embrace a belief in rationality, it is difficult to do anything but embrace rational expectations. To be sure, there is quite a bit of experimental work on such things as preference reversals that might seem to challenge rationality, but theories are rarely abandoned simply because of contrary evidence. What is the alternative to rational expectations? It certainly cannot be adaptive expectations. Indeed, adaptive expectations violates thoroughly the entire corpus of Austrian scholarship. More than any other set of economists, Austrians have 
stressed the forward-looking character of economic action. It is this feature that makes entrepreneurship so central to Austrian economics. It is in acts of entrepreneurship where the future is made. The Lange-Lerner scheme of socialist planning illustrated a version of adaptive expectations, in that it looked backward to what was already known and in existence. There is no way that such a planner could announce prices for what had not yet come into existence.

The other source of particularistic obsolescence for the canonical version of Austrian cycle theory is the portrayal of how a credit expansion generates a general lengthening of the structure of production. Even setting aside questions of expectation and their formation, the canonical story of credit expansion leading to increased roundaboutness is highly particular and neither general nor necessary. In the presence of the small governments and institutional arrangements that existed in the early part of the $20^{\text {th }}$ century, the canonical Austrian formulation had great plausibility. At that time, currency was freely convertible into gold, governments were small, and credit transactions and markets operated and were organized almost wholly within the sphere of private ordering. The world is now ruled by wholly fiat standards. Governments are gigantic. Public ordering is ubiquitous. These modern developments have opened many channels for credit to operate besides the purely private calculus of commercial profitability that was incorporated into the canonical Austrian formulation. To mention just two plausible instances, credit expansion might take the form of booms in real estate markets or securities markets, as against a general lengthening in the structure of production. ${ }^{5}$

What is of continuing value in Austrian cycle theory is its foundational orientation toward a coordinationist style of macroeconomics. In sharp contrast, conventional 
macroeconomics is choice-theoretic and not coordinationist. Macro variables are treated as direct objects of choice, whereas within a coordinationist perspective macro variables are simply phenomena that emerge through interaction among people, but which are not chosen directly by anyone. Central to the entire corpus of Austrian economics is the claim that macro variables are not direct objects of choice but are built up through the interactions among participants within the economic process.

In recent years there has been a growing interest in bringing issues of coordination back into macroeconomics. Much of this has doubtlessly been spurred by a slowly growing recognition of the inadequacies of macro modeling based on single agents or representative individuals. ${ }^{6}$ This growing interest in restoring coordination to a place of prominence in macroeconomic theory surely provides an opportunity for a redeployment of Austrian insights. However, such redeployment would have to involve more than restatement. We are a long way removed from the 1930s, and in a way that would lend a good deal of obsolescence to any effort at restatement, as I have already noted.

Moreover, Austrian cycle theory is actually a blend of two distinct conceptual frameworks that that clash with each other. One is the coordinationist framework where aggregate economic patterns are emergent phenomena. The task of economic analysis within this framework is to explain how orderly patterns of economic activity emerge out of interactions among people. This framework of emergent order is truly central to the Austrian orientation toward the economic process. It was conveyed, however, with the use of a contradictory framework of postulated order. ${ }^{7}$ In this alternative framework, order is not an emergent tendency or property, but rather is a postulate to which the 
theoretical exercise must conform. This framework of postulated general equilibrium renders impotent any formulation that treats aggregate variables as emergent phenomena and not direct objects of choice.

The challenge for Austrian cycle theory is the same as that for coordinationist macroeconomics generally, which is to explain macro phenomena as emergent features of interaction and not as direct objects of choice. The canonical Austrian formulation of a lengthening in the structure of production is simply one particular way of locating coordination and emergence at the core of the macro enterprise. There may be numerous ways that a credit expansion influences macro phenomena, depending on historical and institutional details. In all such instances, however, the Austrian orientation holds that the course of macro variables is to be built up out of interactions among those who participate within the economic process.

\section{Reason, Expectation, and Coordination}

How might elementary requirements of rationality in the formation of expectations operate within the purview of an Austrian-type orientation toward a coordinationist approach to macro phenomena? The use of the faculty of reason to form expectations would surely have to occupy a prominent position in any analytical effort. That expectations are products of reason and imagination is surely noncontroversial at the level of general principle. It is a different matter, however, when it comes to particular methods for implementing that principle. Consider, for instance, the simple expectationaugmented Phillips relationship

$$
Y_{t}=\overline{Y+\gamma}\left(\pi_{t}-\pi_{t}^{e}\right)
$$

that dominates contemporary macro formulations. In this expression, $Y_{t}$ is actual growth in output during period $\mathrm{t}$ and $\bar{Y}$ is the natural rate of growth in the economy. The 
remainder of the equation shows that deviations of the actual from the natural rate of growth depends on the direction and size of the deviation of actual from expected inflation. Save for deviations of actual from expected inflation, the rate of growth would be steady at its natural rate.

Variability in growth rates though time thus depends on inaccuracies in forecasting inflation. Indeed, forecasted inflation is the only variable of relevance for the explanation of why macro variables do not follow some steady-state path. A de-trended flat line is the norm, with variability due either to exogenous shocks to the natural rate of growth or to error in forecasted inflation. Nowhere in this formulation is there any room for macro variability to result from processes of interaction among people. There is simply no room for coordination to proceed with some variable degree of smoothness that, in turn, influences observed macro outcomes. Yet growth is surely an emergent property of an economic system, and it is hardly sensible to treat it as a exogenous shock to that system. Further, the only object of future interest to market participants is a forecast of future inflation. Yet entrepreneurs who made their choices based only on information about probable inflation would be acting foolishly in the extreme. In most instances, a rate of inflation has but limited relevance for economical conduct. It might be of strong concern to bond traders and other dealers in financial paper, but these activities comprise only a small part of the universe of economic activities. For most entrepreneurial activities, a forecast about some average level of future prices is surely of secondary importance. Of much greater importance would be forecasts that pertain to the particular markets in which the entrepreneur is engaged. There would be different particular objects of expectation, depending on the particular activity about which expectations are being formed.

If the course of the economy is built up out of dispersed individual decisions, and with a rate of inflation rarely being a consideration in those decisions, how do expectations about inflation come to command such interest in the macro literature? It 
comes back to the presumption of postulated order. It may be granted that people form expectations over particular variables that are of particular interest in light of their commercial niches. So long as a consistent array of general equilibrium prices is assumed to exist, individual expectations must be consistent with one another, and with all being consistent with some aggregate price level. The postulated order framework thus presumes a consistency and sustainability among plans and prices that makes it plausible to resort to aggregate measures in place of individually-relevant variables.

From a framework of postulated order, Austrian cycle theory would seem to violate elementary requirements of rationality in expectation, because it seems to presume that people cannot distinguish changes in saving from changes in central bank holdings of government debt. A framework of postulated order neuters the economic significance of any distinction between ex ante and ex post, by relegating the distinction to a simple error term. Within a framework of emergent order, by contrast, the distinction between people's ex ante beliefs or expectations and the ex post observations that are revealed as the economic process proceeds is central to many features of the economic process, as is a dissimilarity and divergence among expectations. An economy will be characterized by a plethora of objects of expectation. It would not possess some common object of expectation.

What is the appropriate conceptualization of the macroeconomy? One thing I would say about a good macro theory is that it should be consistent and conformable with the central features of the micro economy. At first glance, this might seem simply to represent a show of support for the literature on microfoundations. ${ }^{8}$ At the level of principle this is correct, but it is not correct with respect to actual practice. I make this distinction between principle and practice out of a recognition that there are two different ways that a principle of microfoundations can be put into practice. The existing literature seeks to postulate choice-theoretic foundations for macroeconomics. The maximization 
of utility by Robinson Crusoe is the paradigmatic model that guides the search for microfoundations. Macro phenomena are simply micro phenomena spoken of more loudly. For instance, individual firms are thought of as moving along supply and marginal product schedules, and it is the same for the aggregate economy.

The alternative to a choice-theoretic foundation for macroeconomics is a coordinationist foundation. ${ }^{9}$ While a choice-theoretic foundation might be workable for a small reclusive tribe here or there, for modern complex societies only exchange and its various extensions can provide a suitable framework for approaching microfoundations. Only in this way can there be an order of movement from simple to complex that corresponds with the distinction between micro and macro. The economy is a dense network of transactions that no one can control or apprehend in its entirety in any great detail. Central planning is impossible, though participants can achieve a generally coordinated pattern of activity with the help of various institutions and conventions that they develop. If macroeconomics rested on adequate microfoundations, it would involve analytical constructs that were consistent with spontaneous order and related notions. To hold that the microeconomy is created through the development of networks of transactions, and then to treat the macro economy in simple choice-theoretic terms is clearly a backwards movement, from more to less complex phenomena. The standard variables of macroeconomics, rates of growth, levels of employment, and rates of inflation, are not objects of choice for anyone, but rather are emergent outcomes of complex economic processes. Governments may do things that might influence the subsequent measures that are assigned to those variables, but this is a very different thing from choosing values for those variables. 
Macro and micro would thus both be concerned centrally with the coordination of economic activities, and would do so within an analytical framework where economic outcomes are not objects of policy choice but emerge through interactions among participants within the economic process. False trading wreaks havoc with the calm facade of postulated order. Yet it is surely a ubiquitous feature of reality that could never be excluded from a framework of emergent order. The distinction between postulated order and emergent order, along with its relevance for macro theory, can be illustrated by comparing the movement of troops on a military parade ground with the movement of people leaving a stadium after an athletic event. The postulated order framework is suitable to explain the movement of troops, for the march has been coordinated in advance. There is no scope for any endogenous source of surprise. Any surprise must be exogenous to the march. A tank might throw a track. A horse might throw its rider. A might faint or die. Observed discoordination can only be exogenous to the coordinator's intentions and plans.

It is wholly different for the spectators leaving an athletic event. The order that results in this case emerges through some process of spontaneous ordering. There is no informative value in stating that the exodus proceeds "as if" it were organized by a coordinator. To do this is simply to clothe ignorance with a fictional garment. There is no coordinator, and the order that results must be explained by other means. Some of these surely involve such conventions as walking on the right, along with some elementary principles of courtesy. Traffic lights and police barricades also help the exodus. These rules and institutions provide a framework that allows a generally orderly exodus to be generated on the spot. Among other things, this exodus will generate 
some volume of false trades as an endogenous part of the process. In some cases there will be sufficient pushing and shoving that causes some people to be injured and require first aid, thereby causing them to be late in arriving at their next appointment. Capital gains and losses are endogenous and anticipatable elements of the emergent order.

Suppose a central bank increases its holding of government debt. It is, of course, a strong empirical regularity that increases in money growth are accompanied by increases in real output in the short run. There are several ways to account for this regularity within the postulated-order context of an expectations-augmented Phillips curve. These mostly involve informational asymmetries and price rigidities of some type. For instance, it might be claimed that entrepreneurs initially interpret price increases incorrectly as signifying increased demands for their particular products. To maintain a crisp focus on the distinction between postulated and emergent order as it pertains to macro theory, however, I will assume that price rigidities are absent and that there is full knowledge of the monetary expansion.

Within the framework of postulated order, there has been no change in real variables and the monetary expansion will have no effect on the real economy. In standard macro terms, the situation just described is one of a vertical Phillips curve, in the short run as well as in the long run. The postulated increase in central bank holdings of government debt present no opportunities for a profitable credit expansion because nothing has changed in real terms, in the aggregate. In this instance, the credit expansion will inject no errors into the economy, entrepreneurial or otherwise.

The same result does not follow, however, from a framework of emergent order. 
For a theory of emergent order, it is not sufficient to compare presumed equilibrium conditions before and after the credit expansion, declare them to be identical, and to conclude from this that the credit expansion had no macro effect. Macro variables are built up or emerge out of interactions among people, and from the perspective of postulated order it is necessary to ask whether a credit expansion, even under the austere conditions postulated above, might lead to changes in the conduct of individual entrepreneurs. If so, macro consequences can arise in the aggregate.

A credit expansion will take place if lenders and potential borrowers recognize opportunities for profitable trade, even if there are no such opportunities in the aggregate. Consider a simple illustration of a model economy where each of 100 lenders had initially extended 100 units of credit. Suppose the central bank's increased holdings of government debt expands potential aggregate lending ability by ten percent. Under the aforementioned situation of postulated order, no opportunities for profitable lending would exist. In this situation the lenders would put their increased reserves into such things as treasury bills. There would be no change in the aggregate volume of loans. This, however, is to derive aggregate outcomes in terms of postulated equilibrium values, and not to derive them through aggregation from market interaction.

There would seem to be a number of avenues by which the central bank purchase of government debt might exert aggregate effects even under the postulated conditions. What matters most of all is whether there are individual contractual opportunities that appear profitable in light of the loosened reserve position of banks. A claim that there are no profit opportunities in the aggregate is irrelevant. The aggregate conditions do not determine the content of individual acts of exchange, for those aggregate conditions 
are rather the reflections of those individual exchanges.

A claim that in the aggregate lenders cannot increase their volume of profitable loans does not mean that no loans will be made. To be sure, this claim involves a presumption of possessing knowledge that is available to no one. But even if that claim is granted purely for the sake of pursuing the argument, the aggregate condition does not guarantee that no new loans will be made. Even if we might grant that the ex post volume of profitable loans might be unchanged, it does not follow that the ex ante plans will start from that resting point. This situation is sensible only in terms of a framework of postulated order, where the economy is presumed to move down unchanging marginal productivity schedules. The most profitable credit contracts are executed first, and the resulting equilibrium pattern of contracts is not changed by the central bank's increased holdings of government debt.

This proposition from comparative statics is, however, a proposition of the logic of postulated relations, and is not adequate for an examination of emergent order where history moves sequentially and uni-directionally. There is plenty of reason to think that ex ante commercial judgments among commercial participants will lead to some credit expansion. Credit contracts are created in a historical sequence, and all of them are thought by the participants to be ex ante profitable. At any subsequent moment, however, some of those contracts will remain profitable while others will seem inferior to new possibilities. In this situation, a credit expansion will allow lenders to exploit new credit opportunities. ${ }^{10}$

Moreover, a claim that on average new profit opportunities do not exist does not bring the matter to a close. Few participants in any field of endeavor think of themselves 
as merely average. The mere making of a claim that there is no change in the total volume of loans that will be profitable does not imply that all lenders will refrain from seeking new business. There is no external selection procedure that selects and matches opportunities with lenders. Rather the selection and matching occurs through an openly competitive process where most competitors think of themselves as above average. In this situation it is surely plausible that some aggregation of ex ante commercial calculations will both lead to an expansion in the volume of loans and bring about a situation that will prove incompatible with the ex post observations that will eventually materialize. To make this latter statement is simply to assert that capital gains and losses are an endogenous part of the economic process, and are not exogenous shocks to some otherwise pre-coordinated process.

\section{Two Types of Cycles and the Problem of Policy}

Traditional Austrian cycle theory treats cycles as undesirable deviations from normally stable conditions. The blame for this instability is generally placed on fractional reserve banking, particularly as supported by central banking, and with central banks often acting to support governmental fiscal policies. The remedies that have appeared in the Austrian literature seek to address these sources of instability in one fashion or another. Currency competition and free banking are at the forefront of most Austrian proposals for a program for economic stability. ${ }^{11}$ Other suggestions can be found in the Austrian literature as well, and there is also some controversy about whether fractional reserve banking should be permitted or should be replaced with a requirement of 100 percent reserves.

It is not my interest here either to support or to dispute Austrian claims about central banking and economic disruption. Rather what I want to do in closing is to point 
to some difficulties in the conventional use of aggregate economic variables to judge economic performance. I would like to do this by advancing two claims: (1) variability in economic time series is not a necessarily sign of poor economic performance and (2) constancy in economic time series is not necessarily a sign of good economic performance.

The original point of departure for Austrian cycle theory was a postulated state of general equilibrium. The normal economy was a flat-line economy, at least after the incorporation of seasonal adjustments. Within this analytical framework, observed variability was a sign of economic miscoordination. The booms and busts characterized by Austrian cycle theory describe an inferior state of affairs relative to the postulated flatline economy of general equilibrum. By contrast, within a framework of emergent order, variability in observed time series can also be a sign of progress in an interdependent world with capital complementarity. There would thus be two types of cycles, one that was consistent with the orderly coordination of economic activities in a complex environment and another that emanated from disruptions to the processes of orderly coordination.

The second claim means that the mere observation of stability in aggregate variables does not mean that coordinative processes are working as well as they might. Consider a simple micro-level illustration of the point I have in mind. An artist who makes pen-and-ink sketches can make 100 pieces ready for sale by working full time, if everything goes well. Suppose a time comes when not everything goes well. While making the frames and mounting the sketches, some of the frames fracture, causing here to divert time from sketching to making more frames. During this period she is able to produce only 80 finished sketches. We would not, however, say experienced an unemployment rate of 20 percent, even though her output of finished product would show such a drop. Rather we would say that her pattern of output shifted, as she made more frames than in previous periods. 
Suppose we analogize the artist's situation to standard macro formulations of shocks to the economy. The first instance is one of full employment equilibrium. In the second instance, her studio is hit with negative shocks that she had not anticipated. Yet full employment continues to exist, only with a different pattern of activities in the face of disruptions then when those disruptions are absent. At the macro level, this second situation would be characterized as involving miscoordination, at least as regarded from a posture of omniscience. A rise in the volume of miscoordination means that there will be some shift of human activity away from executing original plans into activities that revise or reorient plans that have proven unsatisfactory. ${ }^{12}$

An economy can be represented by a network of human activity, some of which is engaged in executing original plans and some of which is engaged in rectifying plans that have judged to have been unsatisfactory. This distinction between types of activity is, of course, an analytical and not an empirical distinction. There is no way, at least so far as I know, that a census could be taken to determine how many people are employed in executing plans and how many are employed in revising plans that have been judged unsuccessful. Yet this analytical distinction follows from the claim that the degree of coordination is a variable that can be influenced, for good or for bad, depending on a variety of institutional arrangements and policy measures. An increase in the volume of miscoordination in a society will shift the pattern of activity in a society, but it need not alter the total volume of activity.

In traditional Austrian cycle theory, micro disruption in the pattern of prices leads to boom followed by bust. Both the boom and the bust result from the reactions of market participants to nonsustainable price signals. There is no need to consider rationality in anticipations again at this point. Still, it does not follow that nonsustainable price signals must show up as variations in aggregate series through time. It is conceivable that miscoordination could increase without any impact on aggregate time series. Miscoordination induces revisions in plans. Labor is shifted from the execution 
of plans to the revision of plans. It is conceivable that this shift of labor can be accommodated within an unchanged aggregate volume of employment.

Using a normative language, cyclical variability may be either good or bad. It depends on the source of the cyclicity. In like manner, the absence of cyclical variability can be either a good thing or a bad thing. It depends on the degree of coordination that is present. A benevolent policy maker would seem to face an insoluble problem of knowledge. It would be necessary to be able to distinguish good cycles from bad, a task rendered even more difficult by a recognition that both features may be present at the same moment. It would also be necessary to when aggregate stability is a sign of a smooth coordination of plans and when it rather means merely a unitary elasticity of movement between the execution of plans and the revision or reassembly of plans.

The active promotion of stability in aggregate time series is neither per se desirable nor is it possible. Aggregate outcomes are emergent outcomes and not direct objects of choice. There is no sense to a policy aimed to prevent cycles, any more then it would be sensible to prevent traffic delays. What is sensible is to seek to preclude unnecessary cycles or disturbances to the coordination of economic activity. Policy for a coordinationist macroeconomics would be of the same genre as policy generally, and would be concerned with providing and maintaining a framework within which people can order their activities. The pursuit of a truly activist stabilization policy will be both impossible and mischievous. Appropriate macro policy cannot aim to achieve particular values for macro variables, for these variables are not objects of choice. Appropriate macro policy is indistinct from appropriate micro policy, and both involve the creation and maintenance of a constitutive framework within which people can generate orderly patterns of economic activity. 


\section{References}

Böhm-Bawerk, Eugon von. Capital and Interest, 3 vols. South Holland, IL: Libertarian Press, 1959 [orig. ed. 1884-1889].

Bryant, John. (1994) "Coordination Theory, the Stag Hunt, and Macroeconomics." In

Friedman, J. W. (Ed) Problems of Coordination in Economic Theory, pp. 207-25. Boston: Kluwer Academic Publishers.

Eggertsson, Thráinn. Economic Behavior and Institutions. Cambridge: Cambridge University Press, 1990.

Foldvary, Fred. "The Business Cycle: A Georgist-Austrian Synthesis". American Journal of Economics and Sociology, 56 (1997): 521-41.

Foss, Nicolai. The Austrian School and Modern Economics. Copenhagen: Munksgaard International Publishers, 1995.

Garrison, Roger W. "The Austrian Theory of the Business Cycle in Light of Modern Macroeconomics." Review of Austrian Economics, 3 (1989): 3-29.

Garrison, Roger W. "New Classical and Old Austrian Economics: Equilibrium Business Cycle Theory in Perspective." Review of Austrian Economics, 5 (1991): 91-103.

Gordon, Robert Aaron. Business Fluctuations, $2^{\text {nd }}$ ed. New York: Harper and Row, 1961 [orig. ed. 1952].

Haberler, Gottfried. Prosperity and Depression, $5^{\text {th }}$ ed. London: Allen \& Unwin, 1964 [orig. ed. 1937].

Hayek, Friedrich A. Prices and Production, $2^{\text {nd }}$ ed. London: Routledge and Kegan Paul, 1935.

Hayek, Friedrich A. Denationalisation of Money. London: Institute of Economic Affairs, 
1976.

Hutt, William H. "The Concept of Waste." South African Journal of Economics, 11 (1943): 1-10.

Janssen, Maarten C. W. Microfoundations: A Critical Inquiry. London: Routledge, 1993.

Kirman, Alan P. "Whom or What Does the Representative Individual Represent?" Journal of Economic Prespectives 6 (1992): 117-36.

Leijonhufvud, Axel. Information and Coordination. New York: Oxford University Press, 1981.

Macfie, Alec. Theories of the Trade Cycle. London: Macmillan, 1934.

Mises, Ludwig von. The Theory of Money and Credit. London: Jonathan Cape, 1934 [orig. ed 1912].

O'Driscoll, Gerald P. Jr. Economics as a Coordination Problem. Kansas City: Sheed Andrews, 1977.

Selgin, George A. The Theory of Free Banking. Totowa, NJ: Rowman \& Littlefield, 1988.

Vaughn, Karen I. Austrian Economics in America. New York: Cambridge University Press, 1994.

Wagner, Richard E. "Austrian Cycle Theory: Saving the Wheat while Discarding the Chaff." Review of Austrian Economics 12 (1999): 65-80.

White, Lawrence H. Competition and Currency. New York: New York University Press, 1989.

Wicksell, Knut. Interest and Prices. London: Macmillan, 1936 [orig. ed, 1898].

Witt, Ulrich. "The Hayekian Puzzle: Spontaneous Order and the Business Cycle." 
Scottish Journal of Political Economy 44 (February 1997): 44-58.

\section{ENDNOTES}

${ }^{1}$ An earlier version of this paper was presented at a workshop on "New Perspectives on Austrian Economics," held at the Max Planck Institute in Jena, 7-8 August 1998. I am particularly grateful to Nicolai Foss, Sylvie Geisendorf, Ulrich Witt, and Michael Wohlgemuth for their comments and suggestions at that time. A revised version of that paper was published as (Wagner 1999), and this paper addresses similar themes in a somewhat different manner.

${ }^{2}$ It is possible to argue that the period of production has some useful heuristic properties even if it must also be acknowledged that there is no way of developing a coherent measure of the period of production.

${ }^{3}$ See, for instance, Gerald O'Driscoll (1977) and Roger Garrison (1989)(1991).

${ }^{4}$ For sharply contrasting assessments of that resurgence, compare Nicolai Foss (1995) and Karen Vaughn (1994).

${ }^{5}$ For an effort to reconcile some of the Austrian insights with real estate booms, see Fred Foldvary (1997).

${ }^{6}$ For a splendid, pithy examination of the dead ends to which a non-coordinationist macroeconomics leads, see Alan Kirman (1992).

${ }^{7}$ This point is developed crisply in Ulrich Witt (1997.

${ }^{8}$ For a lucid and penetrating survey of this literature, see Maarten Janssen (1993).

${ }^{9}$ See, for instance, Axel Leijonhufvud (1981) and John Bryant (1994). 
${ }^{10}$ To be sure, the emergence of secondary markets, whereby an original lender sells a note to someone else operates in a somewhat similar manner. Indeed, the emergence of such secondary market arrangements is itself an endogenous market phenomena that is best treated in light of a theory of spontaneous order applied to institutional development, a nice survey of which is presented in Thráinn Eggertsson (1990). ${ }^{11}$ See, for instance, F. A. Hayek (1976), George Selgin 1988), and Lawrence White (1989).

${ }^{12}$ Such miscoordination can be categorized as wasteful, as explained in W. H. Hutt (1943). 